\title{
Adsorption Efficiency of Powdered Activated Carbon Applied to a Filter Bed
}

\author{
Andrzej Bielski ${ }^{1 *}$, Wiesław Zymon ${ }^{1}$, Tadeusz Żaba ${ }^{1,2}$ \\ 'Institute of Water Supply and Environmental Protection, Faculty of Environmental Engineering, \\ Kraków University of Technology, Warszawska 24, 31-155 Kraków, Poland \\ ${ }^{2}$ Kraków Waterworks, Senatorska 1, 30-106 Kraków, Poland
}

Received: 28 September 2016

Accepted: 12 December 2016

\begin{abstract}
This paper presents a study on adsorption of organic pollutants present in natural water on powdered activated carbon (PAC). Surface water was treated for municipal purposes at a water treatment plant. Currently used technological systems poorly utilize PAC adsorption capacity due to a small driving force of a mass exchange between water and sorbent. Additionally, the adsorption process takes place in volume systems with simultaneous coagulation. The authors proposed a new method where adsorption was carried out in a filter bed with PAC applied to its upper layer. The powdered sorbent was applied to the bed at the end of backwashing. This way an extended contact time between water and PAC was assured, which enhanced utilization of carbon sorption capacity. Comparative studies were also performed with adsorption in a volume system. The results confirmed that the filter bed showed a better utilization of PAC adsorption capacity than the volume system. The authors developed the PAC adsorption models in unsteady states for both volume and filter systems. Simulations confirmed that a utilization rate of PAC adsorption capacity in the filter can be several times higher than in volume systems that are commonly used for adsorption and coagulation.
\end{abstract}

Keywords: adsorption, PAC, filtration, water treatment, wastewater treatment, organic pollutants

\section{Introduction}

The removal of organic pollutants from natural waters is one of the fundamental problems in potable water treatment. They may be responsible for unpleasant odor and taste of water, can negatively affect consumer health, and may act as precursors of harmful oxidation byproducts. Common water treatment technologies that use

*e-mail: abielski@riad.usk.pk.edu.pl

coagulation, filtration, disinfection, or intermediate preoxidation cannot always remove organic compounds in a sufficient way. Therefore, additional adsorption processes should be employed at different stages of water treatment systems. Generally, there are two methods of adsorption on activated carbon. The first utilizes powdered activated carbon (PAC) in a volume process (with coagulation) while the other uses particulate or granular-activated carbon in a filter; the former is preferred when risks of failure to meet drinking water quality parameters occur only occasionally [1-2]. 
Applying PAC to remove natural organic compounds and THM precursors from water has been analyzed by [2-9]. Based on the literature, the removal of dissolved organic substances (measured as DOC) and THM precursors depends on many factors: characteristics of pollutants, their concentrations, types of carbon, process parameters, and more. The PAC doses applied during the process remained within the range of tens to hundreds of grams per cubic meter.

\section{A New Concept of PAC Application During Water Filtration}

The proposed method involves the use of PAC to adsorb pollutants remaining after coagulation and sedimentation. Filters with two or three layers should be used in this method. In the case of a two-layer filter bed, PAC is applied to the upper layer (i.e., anthracite) during its fluidization at the end of filter backwashing. Once activated carbon has been applied, backwash flow is turned off and the bed of anthracite is embedded within powdered activated carbon. A sand layer protects the filter against carbon particle washout. During filtration, solids and dissolved substances are adsorbed onto PAC and removed from water. The frequency of filter backwashing depends on the rate of exhaustion of PAC adsorption capacity.

In such a filter (PAC filter) the sorbent remains in contact with organic pollutants at concentrations comparable to the feed concentrations for a relatively long time (several tens of hours, depending on the filter cycle), while in batch homogeneous units with plug or dispersed flows (e.g., flocculators) concentrations of adsorbate in contact with PAC are lower. Accordingly, the driving force behind the adsorption rate in the filter will be greater than in other units, and PAC adsorption capacity can be utilized in a more efficient way. To match the effects obtained in the PAC filter, higher doses of the sorbent had to be employed in other units. A series of tests was performed to determine whether the new system could be successfully used and to demonstrate its better utilization of PAC adsorption capacity

\section{Water Treatment Process}

Our study took place at the Dłubnia Water Treatment Plant (WTP) in Kraków:

- Water from the Dłubnia River passes to primary settling tanks and then to a well; water is pumped from there to the water treatment line.

- Then water passes to high-speed mixers. Coagulant and occasionally PAC (depending on water quality) are dosed to pipes ahead of the mixers. After rapid mixing water flows through an overflow pipe to a main pipe, which distributes water to flocculators.

- Flocculation and flocculation combined with PAC adsorption (occasionally) are carried out in five flocculators, each one consisting of two chambers. Water from the flocculators is discharged to a multichamber settling tank.
- Flocks settle in the settling tank comprising five chambers. The sludge is removed from the settling tank by mechanical scrapers in a periodic mode. Water from the settling tank passes is pumped to filters.

- Ten rapid filters operate during normal conditions. They are equipped with block drainage and do not have a supporting layer. The filter bed consists of three layers (garnet, sand, anthracite).

- The water is disinfected with chlorine dioxide. A chlorine dioxide solution is dosed into the pipe ahead of the contact tank.

\section{Material and Methods}

\section{Tests on PAC Adsorption with Simultaneous Coagulation in a Volume System}

Currently, the PAC adsorption process takes place during coagulation at the WTP and PAC is dosed to water right after coagulant. The study on PAC adsorption was performed with beaker tests and a laboratory mixing set. Such tests can accurately reproduce the actual processes taking place in the volume systems (batch or plug flow reactors). The adsorption values, determined during the tests, could be used to design the actual technological systems and to determine the required PAC doses.

Raw water from the WTP was used in the tests. There were 6 experimental series. The water was poured into the $1 \mathrm{dm}^{3}$ beakers and then the coagulant PAX-16 was added; the coagulant dose was $2.0 \mathrm{~g} \mathrm{Al} / \mathrm{m}^{3}$. After 30 seconds, PAC doses ranging from 0 to $50 \mathrm{~g} / \mathrm{m}^{3}$ were added to the beakers. Then after 20, 40, and 60 minutes the samples were taken for further analysis. They settled for $5 \mathrm{~min}$ and the remaining solids were removed by centrifugation. The UV absorbance of $254 \mathrm{~nm}$ was measured in the samples.

\section{Adsorption in the PAC Filter}

Water after coagulation and sedimentation was filtered in two identical filters. The columns were filled with sand and anthracite; a granulometric characteristic of the filter bed was kept the same as at the water treatment plant. The research was carried out in two parallel filters and PAC suspension was fed to the anthracite layer of one of the filters, after its backwashing.

The study used two columns of diameter $\mathrm{d}=0.150 \mathrm{~m}$. The filter layers included a bottom gravel layer of $0.15 \mathrm{~m}$, a middle sand layer of $0.5 \mathrm{~m}$, and a top anthracite layer of $0.5 \mathrm{~m}$. The set of valves enabled a filtrate discharge and filter backwashing with tap water. Water after coagulation and sedimentation (settling tank) was pumped to the filters by a metering pump of variable capacity. Filtration rate was kept constant at $5 \mathrm{~m} / \mathrm{h}$ and the filters were operating in a downflow mode. PAC was applied only to one of the filters. The PAC suspension was introduced to the anthracite layer using a metering pump. Then PAC was spread evenly throughout the layer during fluidization (expansion 5\%) until carbon traces were observed above 
the bed. Next, the water flow was shut off to let the anthracite and PAC layer settle. The water level over the filter bed was slowly stabilized down to the initial height at which the filter operation had started. Once the filter bed was ready for operation, water from the settling tank was pumped to the PAC filter as well as to the other filter column without PAC. Every two hours samples of feed water were collected by the peristaltic pump while the filter effluent samples were collected by the automatic water sampler at fixed times. After the cycle we determined absorbance at $254 \mathrm{~nm}$ and TOC. There were 12 filtration cycles. The doses of PAC applied to the filter were 21, 42, and $63 \mathrm{~g}$.

\section{Adsorption Models}

The models presented in this section discuss the concentration of adsorbate $\mathrm{C}$ in a liquid phase. The absorbance measured at UV light of $254 \mathrm{~nm}\left(\mathrm{~A}_{254}\right)$ is used to determine dissolved organic pollutants. Absorbance $\mathrm{A}$ is approximately proportional to concentration $\mathrm{C}$. Therefore, the models are also valid for absorbance ( $\mathrm{C}$ can be replaced by $\mathrm{A}$ in the equations). We used the dilution method to establish that the dimensionless concentration $\mathrm{C} / \mathrm{C}_{0}$, for absorbance A from 0 to $3.6390 \mathrm{~m}^{-1}$, varies approximately linearly. Equation $\mathrm{C} / \mathrm{C}_{0}=0.2748^{*} \mathrm{~A}$ was obtained, in which $\mathrm{C}_{0}$ is the initial concentration of organic compounds shawing absorbance $\mathrm{A}$ in $\mathrm{UV}_{254 \mathrm{~nm}}$. For this formula, correlation coefficient was equal to 0.9996 . The average relative error for the dimensionless concentrations $\mathrm{C} / \mathrm{C}_{0}$ was calculated using this formula equal to $2.5 \%$.

\section{Adsorption in a Volume System}

Mass exchange rates between a solution and a sorbent in a volume system are described by the set of equations [10-14]:

$$
\begin{gathered}
\frac{d C}{d t} \varepsilon_{m}=-k \cdot a_{m} \cdot D \cdot \frac{\rho_{w}}{\rho_{u}} \cdot\left(C-C_{i}\right) \\
\frac{d a}{d t}\left(1-\varepsilon_{m}\right)=+k \cdot a_{m} \cdot D \cdot \frac{1}{\rho_{u}}\left(C-C_{i}\right)
\end{gathered}
$$

...where:

$\mathrm{C}$ - adsorbate concentration in water $\left(\mathrm{g} / \mathrm{m}^{3}\right)$

$\mathrm{C}_{\mathrm{i}}$ - equilibrium concentration in water $\left(\mathrm{g} / \mathrm{m}^{3}\right)$

$\mathrm{k}$ - mass transfer rate constant across a water-sorbent interface $(\mathrm{m} / \mathrm{s})$

$a_{m}-$ specific outer surface of sorbent particles $\left(\mathrm{m}^{2} / g\right.$ of sorbent)

$\mathrm{D}$ - sorbent dose ( $\mathrm{g}$ of sorbent $/ \mathrm{m}^{3}$ of system)

$\rho_{\mathrm{w}}$ - water density $\left(10^{6} \mathrm{~g} / \mathrm{m}^{3}\right)$

$\rho_{\mathrm{u}}$ - system density $\left(\mathrm{g} / \mathrm{m}^{3}\right.$ of system)

$\varepsilon_{\mathrm{m}}$ - mass share of water in a water-sorbent system

$\mathrm{a}$ - adsorption quantity ( $\mathrm{g} / \mathrm{g}$ of sorbent)

$\mathrm{t}$ - time (s)

... unless sorbent dose $\mathrm{D}$ is not very low: $\rho_{\mathrm{u}} \approx \rho_{\mathrm{w}}+\mathrm{D}$ , while $\varepsilon_{\mathrm{m}} \approx \rho_{\mathrm{w}} /\left(\rho_{\mathrm{w}}+\mathrm{D}\right)$.
A relationship between equilibrium concentration $\mathrm{C}_{\mathrm{i}}$ and the actual adsorption quantity, a, comes from adsorption isotherms:

- Henry's isotherm:

$$
C_{i}=\frac{a}{\Gamma}
$$

- Langmuir isotherm:

$$
C_{i}=\frac{a \cdot b}{a_{\max }-a}
$$

$\Gamma$ - Henry's constant ( $\mathrm{m}^{3}$ of water/g of sorbent)

$\mathrm{a}_{\max }$ - maximum adsorption capacity (asymptote of the Langmuir isotherm) ( $\mathrm{g} / \mathrm{g}$ of sorbent)

$\mathrm{b}$ - Langmuir isotherm's constant $\left(\mathrm{g} / \mathrm{m}^{3}\right.$ of water)

When the adsorption equilibrium is described by Henry's isotherm there is the analytical solution of equations (1) and (2). Substituting the equilibrium concentration $\mathrm{C}_{i}$ with (3), the solution of equations (1) and (2) at the initial condition:

$$
C(t=0)=C_{0}
$$

$\ldots$ is as follows:

$$
C=\frac{\beta}{\omega}+\left(C_{0}-\frac{\beta}{\omega}\right) \exp (-\alpha \cdot \omega \cdot t)
$$

... where:

$$
\begin{gathered}
\alpha=k \cdot a_{m} \cdot D \cdot \frac{\rho_{w}}{\rho_{u}} \cdot \frac{1}{\varepsilon_{m}} \\
\beta=\frac{a_{0}}{\Gamma}+\frac{\varepsilon_{m}}{\rho_{w}\left(1-\varepsilon_{m}\right)} \frac{C_{0}}{\Gamma} \\
\omega=1+\frac{\varepsilon_{m}}{\rho_{w}\left(1-\varepsilon_{m}\right)} \frac{1}{\Gamma}
\end{gathered}
$$

Equation (6) has been used to determine the product $k \cdot a_{m}$, which characterizes a substitute transfer rate constant across the water-sorbent interface for the specific sorbent and at specific hydrodynamic conditions. To determine $\alpha$ (Eq. (7)), dose D was assumed to be the mass of sorbent introduced to the unit water volume, instead to the unit water-sorbent volume, since both are practically the same.

\section{Adsorption in a Column System}

Transport of an adsorbate in an adsorption column can be described by the advection and diffusion equation, taking into account the adsorption rate as follows [10-14]: 
$\frac{\partial C}{\partial t} \varepsilon+V_{x} \frac{\partial C}{\partial x}=D_{x} \frac{\partial^{2} C}{\partial x^{2}}-k \cdot a_{m} \cdot \rho_{p, s o r b} \cdot\left(C-C_{i}\right)$

... where:

$\mathrm{V}_{\mathrm{x}}$ - empty bed (column) velocity $(\mathrm{m} / \mathrm{s})$

$\mathrm{D}_{\mathrm{x}}$ - mass dispersion coefficient at the empty bed $\left(\mathrm{m}^{2} / \mathrm{s}\right)$

$\varepsilon-$ filter bed porosity

$\rho_{p, s o r b}-$ apparent density of sorbent applied to the column $\left(\mathrm{g} \mathrm{sorb} / \mathrm{m}^{3}\right), \rho_{p, \text { sorb }}=m_{\text {sorb }} / V$

$\mathrm{V}$ - volume of the adsorption column $\left(\mathrm{m}^{3}\right)$

$\mathrm{x}$ - linear coordinate $(\mathrm{m})$

(others as above)

Adsorption quantity $\mathrm{a}^{*}$ in a fixed adsorption layer is described with equation:

$$
\frac{\partial a^{*}}{\partial t}(1-\varepsilon)=k \cdot a_{m} \cdot \rho_{p, s o r b} \cdot\left(C-C_{i}\right)
$$

... where:

$\mathrm{a}^{*}$ - adsorption quantity $\left(\mathrm{g} / \mathrm{m}^{3}\right.$ of sorbent),

$a^{*}=a \cdot \rho_{p, s o r b} /(1-\varepsilon)$

(others as above)

To integrate equations (10) and (11) the adsorption isotherm has to be identified. In this case, Henry's isotherm has the form:

$$
a^{*}=\Gamma^{*} C_{i}
$$

$\Gamma^{*}-$ Henry's constant ( $\mathrm{m}^{3}$ of water $/ \mathrm{m}^{3}$ of sorbent),

$$
\Gamma^{*}=\Gamma \cdot \rho_{p, s o r b} /(1-\varepsilon)
$$

(others as above)

The set of equations (10) and (11) together with isotherm (12) were solved numerically [12-13]. Equation (10) was integrated after its decomposition [12-13]. First, integration was performed for adsorbate advection, including the adsorption rate, and then for mass dispersion. Such a procedure reduces the distorting effects that numerical diffusion has on the calculated concentrations

Fig. 1.

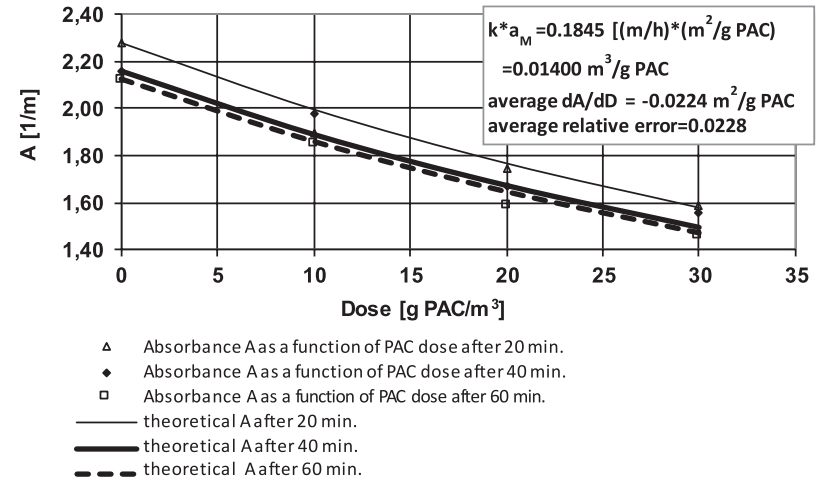

and adsorption quantity. A computer program used for calculating mass transport with a simultaneous adsorption in transient flows and concentrations in open channels, was adapted and used to solve the problem. The program performs calculations for the filter bed with no adsorption in a lower layer [12-13] and allows us to carry out calculations for filter beds with variable dispersion and adsorption properties along the column when flows and concentrations of dissolved pollutants vary in time.

\section{Operation of a Filter Column with PAC (PAC Filter)}

Concentrations of the pollutants adsorbed on PAC and retained on the other filter layers in the PAC filter can be based on the model of column adsorption and the effluent concentrations from the filter with no PAC. It is assumed that flows $\mathrm{Q}_{0}$ and feed concentrations of the pollutants $\mathrm{C}_{0}$ to both filters are the same. If the effluent concentrations from the filter with no PAC are known at intervals $\Delta t$, then after a time period equal to $i^{*} \Delta t$ the effluent concentration from the filter with PAC will be as follows [14]:

$$
C_{i, P W A}=C_{0}-\left(C_{i}-C_{i, P W A}^{*}\right)
$$

...where:

$\mathrm{C}_{0}$ - concentrations in the influent to filters with and without PAC $\left(\mathrm{g} / \mathrm{m}^{3}\right)$

$\mathrm{C}_{\mathrm{i}}$ - concentrations in the effluent from the filter without PAC after $\left(i^{*} \Delta \mathrm{t}\right)\left(\mathrm{g} / \mathrm{m}^{3}\right)$

$\mathrm{C}_{\mathrm{i}, \mathrm{PWA}}$ - expected concentration in the effluent from the filter with PAC after $(i * \Delta t)$ if filter had only a PAC layer $\left(\mathrm{g} / \mathrm{m}^{3}\right)$

$\mathrm{C}^{*}{ }_{\mathrm{iPWA}}-$ concentrations in the effluent from the filter with PAC after $\left(i^{*} \Delta \mathrm{t}\right)\left(\mathrm{g} / \mathrm{m}^{3}\right)$

$\mathrm{Q}_{0}$ - flow rate to the filters $\left(\mathrm{m}^{3} / \mathrm{s}\right)$

$\Delta \mathrm{t}$ - time interval (s)

Equation (14) enables us to determine the adsorbate concentrations in the effluent from the PAC filter as a result of adsorption on PAC only. Equation (14) also describes the difference in operation efficiency between the filter with PAC and without PAC. The concentrations $C_{i, P W A}$ may

Fig. 2.

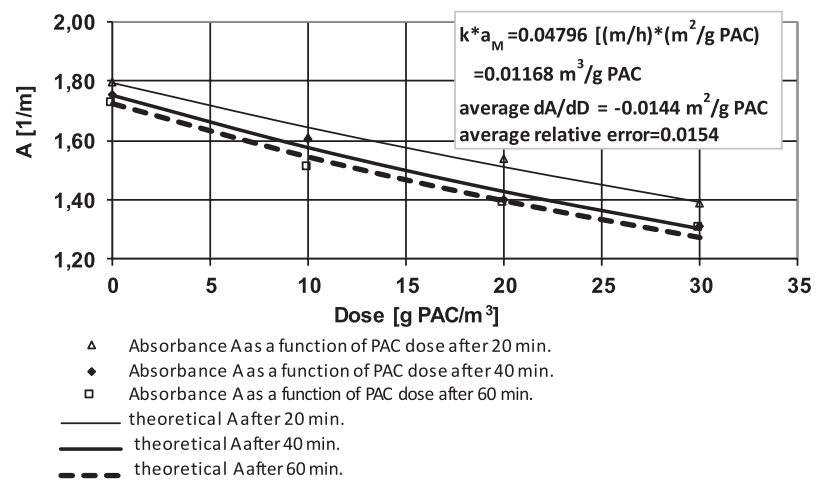

Figs 1 and 2. Absorbance A as a function of PAC doses and time during adsorption in a volume system. 


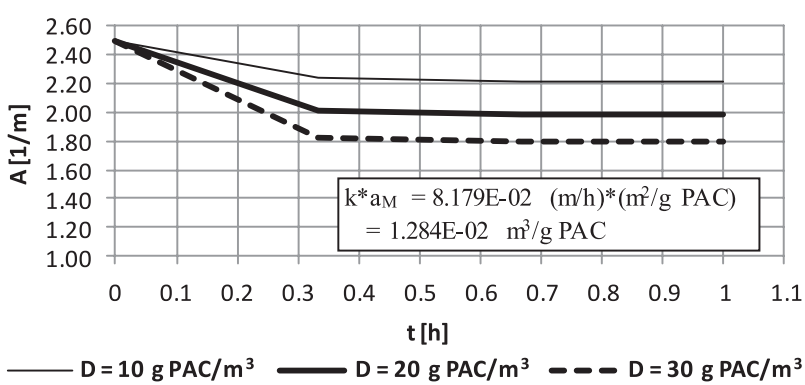

Fig. 3. Absorbance A versus time for different PAC doses, as determined from the model of adsorption with coagulation in the volume system (average values of model parameters).

be used to estimate parameters of the adsorption model in the PAC filter. Equation (14) determines $C^{*}{ }_{i P W A}$ in the effluent from the PAC filter, as a result of filtration without $\mathrm{PAC}$ and adsorption on PAC, and then:

$$
C_{i, P W A}^{*}=C_{i}+C_{i, P W A}-C_{0}
$$

Equation (15) becomes a model describing the operation of the PAC filter. In Equation (15), $C_{i, P W A}$ results from the adsorption model in a filter column, while $C_{i}$ is the adsorbate concentration measured in the effluent from the filter without PAC; $C_{0}$ is the adsorbate concentration in the feed to both filters.

\section{Results and Discussion}

\section{Adsorption on PAC with Simultaneous Coagulation in the Volume System}

The results of laboratory studies on PAC adsorption with coagulation enabled us to determine the parameters of the adsorption model in the volume system (batch or a plug flow flocculator), as described in paragraph Adsorption in a volume system. The model helps to determine changes in absorbance of the aqueous solution and changes of PAC adsorption in relation to time and a sorbent dose.

Some test results and theoretical calculations are presented in Figs 1 and 2.

During the research studies $\mathrm{k}^{*} \mathrm{a}_{\mathrm{M}}$ and $\Gamma$ were determined for the adsorption model in volume systems (1), (2), and (3). The average parameters of the adsorption model with a simultaneous coagulation in the volume system (batch or a plug flow flocculator) are: $\mathrm{k}^{*} \mathrm{a}_{\mathrm{M}}=8.179 \mathrm{E}-02 \pm 6.085 \mathrm{E}-02$ $(\mathrm{m} / \mathrm{h}) *\left(\mathrm{~m}^{2} / \mathrm{g}\right.$ PAC $), \Gamma=1.284 \mathrm{E}-02 \pm 2.196 \mathrm{E}-03 \mathrm{~m}^{3} / \mathrm{g}$ PAC; a significant variability of $\mathrm{k}^{*} \mathrm{a}_{\mathrm{M}}$ is probably caused by the changing characteristic of water samples.

The curves representing absorbance vs. both a PAC dose and time in different experiments have similar slopes, which means that adsorption is fast, runs nearly through the equilibrium states, and is almost exclusively PAC dosedependent (Figs 1 and 2). For the average values of $\mathrm{k}^{*} \mathrm{a}_{\mathrm{M}}$ and $\Gamma$, and for the initial absorbance of $2.5 \mathrm{~m}^{-1}$, the average slope of the curves $(\mathrm{dA} / \mathrm{dD})$ was $-0.0232 \mathrm{~m}^{2} / \mathrm{g}$ PAC. The
Fig. 4.

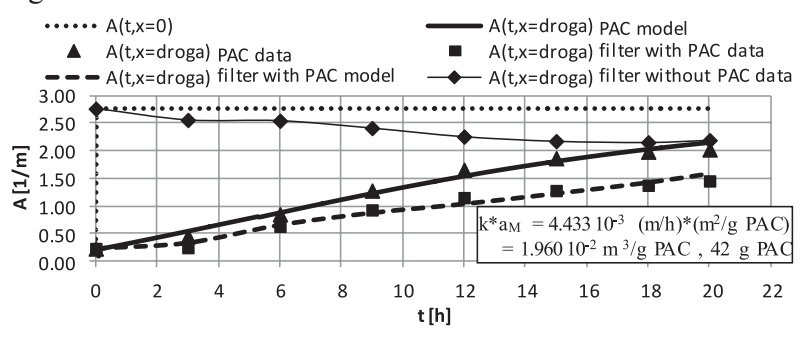

Fig. 5.

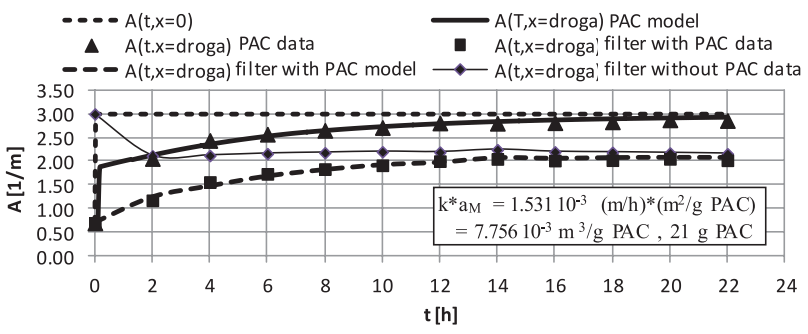

Fig. 6.

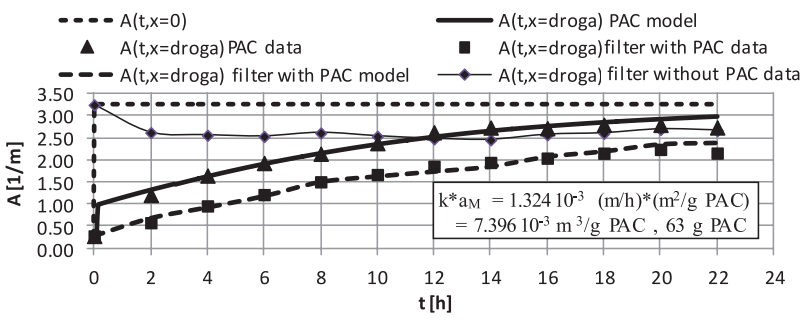

Figs 4, 5, and 6. Absorbance A vs. time in the efluent from the filter without PAC, with PAC and adsorption on PAC only obtained from measurements (data) and the model calculations (flow $=0.087 \mathrm{~m}^{3} / \mathrm{h}, \mathrm{x}=0$ means top, and $\mathrm{x}=$ droga means the bottom cross-section of the filter).

course of absorbance A over time for different PAC doses (Fig. 3) proves that adsorption runs through equilibrium states. Absorbance A virtually does not undergo further changes after about $0.333 \mathrm{~h}$.

Squared correlation coefficients $\mathrm{R}^{2}$ for models (1), (2), and (3) ranged from 0.864 to 0.970 and were sufficiently high to prove a well-fitting model. The average relative fitting error was low (0.0217) and its deviation was small (0.0063). Such a low average relative error confirms that the model fits the measurements well.

\section{Effect Filtration Through the Bed Containing PAC}

Figs 4, 5, and 6 illustrate changes of absorbance A in the effluent from the filter without PAC, with PAC, and adsorption on PAC only. The data were obtained from direct measurements and the model calculations for various PAC masses. The theoretical curves fit the recorded absorbance measurements well. The average relative error of the model fit is low (0.0394) and the deviation is small (0.0221). Such a low average relative error confirms that the model fits the measurements well. 
Table 1. Comparison of PAC adsorption in the filter and in the plug flow flocculator.

\begin{tabular}{|c|c|c|c|c|c|}
\hline $\begin{array}{c}\text { Mass of PAC applied } \\
\text { to the filter } \\
\text { (g PAC) }\end{array}$ & $\begin{array}{c}\text { Average } \\
\text { equivalent dose of } \\
\text { PAC per a filtrate } \\
\text { volume } \\
\mathrm{D}_{1}\left(\mathrm{~g} / \mathrm{m}^{3}\right)\end{array}$ & $\begin{array}{l}\text { Average amount of } \\
\text { organic pollutants } \\
\text { removed in the PAC filter } \\
\text { (absorbance units) } \\
\mathrm{a}_{1}\left(\mathrm{~m}^{3} /\left(\mathrm{m}^{*} \mathrm{~g}\right)\right)\end{array}$ & $\begin{array}{l}\text { Average amount of organic } \\
\text { pollutants removed in } \\
\text { the plug flow flocculator } \\
\text { (absorbance units) } \\
\mathrm{a}_{2}\left(\mathrm{~m}^{3} /\left(\mathrm{m}^{*} \mathrm{~g}\right)\right)\end{array}$ & $\begin{array}{l}\text { PAC dose to } \\
\text { the plug flow } \\
\text { flocculator } \\
\mathrm{D}_{2}\left(\mathrm{~g} / \mathrm{m}^{3}\right)\end{array}$ & $\mathrm{D}_{2} / \mathrm{D}_{1}$ \\
\hline 21 g PWA (average values) & 10.0 & 0.031 & 0.026 & 12.4 & 1.2 \\
\hline 42 g PWA (average values) & 22.7 & 0.049 & 0.015 & 74.8 & 3.3 \\
\hline $63 \mathrm{~g}$ PWA (average values) & 42.9 & 0.022 & 0.018 & 53.6 & 1.2 \\
\hline
\end{tabular}

The test results enabled us to determine $\mathrm{k}^{*} \mathrm{a}_{\mathrm{M}}$ and $\Gamma$ for the adsorption model in column systems (10), (11), and (12). The average model parameters varied, depending on the PAC mass introduced to the filter:

$-21 \mathrm{~g}$ of PAC: $\quad \mathrm{k}^{*} \mathrm{a}_{\mathrm{M}}=1.779 \mathrm{E}-03 \pm 5.858 \mathrm{E}-04$

$(\mathrm{m} / \mathrm{h}) *\left(\mathrm{~m}^{2} / \mathrm{g}\right.$ PAC $)$

$\Gamma=9.600 \mathrm{E}-03 \pm 2.962 \mathrm{E}-03 \mathrm{~m}^{3} / \mathrm{g}$ PAC

$\rho_{\mathrm{p}, \mathrm{sorb}}=2.3767 \mathrm{E}+03 \mathrm{~g} / \mathrm{m}^{3}$

- 42 g of PAC: $\quad \mathrm{k}^{*} \mathrm{a}_{\mathrm{M}}=3.520 \mathrm{E}-03 \pm 9.133 \mathrm{E}-04$

$(\mathrm{m} / \mathrm{h}) *\left(\mathrm{~m}^{2} / \mathrm{g}\right.$ PAC $)$

$\Gamma=1.807 \mathrm{E}-02 \pm 4.725 \mathrm{E}-03 \mathrm{~m}^{3} / \mathrm{g}$ PAC

$\rho_{\mathrm{p}, \mathrm{sorb}}=4.7534 \mathrm{E}+03 \mathrm{~g} / \mathrm{m}^{3}$

$-63 \mathrm{~g}$ of PAC: $\quad \mathrm{k}^{*} \mathrm{a}_{\mathrm{M}}=1.811 \mathrm{E}-03 \pm 6.869 \mathrm{E}-04$

$(\mathrm{m} / \mathrm{h}) *\left(\mathrm{~m}^{2} / \mathrm{g}\right.$ PAC $)$

$\Gamma=7.552 \mathrm{E}-03 \pm 4.401 \mathrm{E}-04 \mathrm{~m}^{3} / \mathrm{g}$ PAC

$\rho_{\mathrm{p}, \mathrm{sorb}}=7.1301 \mathrm{E}+03 \mathrm{~g} / \mathrm{m}^{3}$

Individual PAC masses have different apparent PAC densities $\rho_{\mathrm{p} \text {,sorb }}$ in the filter. The highest values of $\mathrm{k}^{*} \mathrm{a}_{\mathrm{M}}$ were obtained for $42 \mathrm{~g}$ of PAC. This amount of PAC is therefore strongly preferred with regard to adsorption efficiency. The filtration velocity $\mathrm{V}^{*}=\mathrm{V}_{\mathrm{x}} / \varepsilon=2.384 \cdot 10^{-3}$ and the mass dispersion coefficient $\mathrm{D}_{\mathrm{x}}^{*}=\mathrm{D}_{\mathrm{x}} / \varepsilon=2.458 \cdot 10^{-5}$ $\mathrm{m}^{2} / \mathrm{s}$ were determined in separate studies.

The actual adsorption of organic compounds on PAC may be disturbed by other processes leading to a re-duction in the removal of organic compounds from water. PAC is capable of adsorbing inorganic polymers. In the case of low mass of PAC introduced into the filter (e.g., $21 \mathrm{~g}$ or $2.38 \mathrm{~kg}$ of $\mathrm{PAC} / \mathrm{m} 3$ of bed) adsorption of these polymers may substantially suppress adsorption capacity of the sorbent. The equilibrium constant of the adsorption isotherm for organic compounds is low. Adsorption of polymers and colloids reduces the mass transfer rate to PAC particles. In this case, efficiency of adsorption of organic compounds on PAC in the filter is low compared to PAC adsorption with coagulation. A higher PAC mass applied to the filter (i.e., $42 \mathrm{~g}$ or $4.75 \mathrm{~kg} \mathrm{PAC} / \mathrm{m}^{3}$ of bed) increases the share of sorbent particles in the total mass of PAC-adsorbing organic compounds from water, and Henry's constant in the adsorption isotherms is almost doubled. This results in a significant increase of PAC utilization efficiency in the filter. The efficiency exceeds the efficiency of sorbents observed during PAC adsorption with coagulation. A further increase of PAC mass intro- duced into the filter up to $63 \mathrm{~g}\left(7.13 \mathrm{~kg}\right.$ of $\mathrm{PAC} / \mathrm{m}^{3}$ of bed $)$ reduces sorbent utilization efficiency. The effect is probably related to the different physical mechanisms associated with sorption of adsorbates.

A higher mass of PAC in the filter increases the amount of coal particles in pores of low diameters, resulting in flow obstruction. The blocking is even stronger since some particles present in water are retained on the PAC particles and therefore they cannot participate in adsorption. A high rate of clogging is observed in the upper layers and the PAC particles are coated with colloids. This way a large part of the sorbent cannot participate in adsorption of organic pollutants. In addition, PAC particles may form multilayer coatings that hinder adsorption. These effects are confirmed by the lower Henry's constant $\Gamma$ in the isotherm equation and the lower $\mathrm{k}^{*} \mathrm{a}_{\mathrm{M}}$ in the mass transfer rate equation. The presented method of PAC application to the filter is hardly reproducible. It also does not guarantee a uniform distribution of the sorbent along the filter height. An uneven PAC distribution within the filter is the primary factor responsible for significant changes in the adsorption effects during individual filter cycles with the same mass of PAC used.

\section{Comparative Study on Removal of Organic Pollutants from Water with PAC}

Based on the results obtained from the individual filter cycles, the mass balances of substances identified by absorbance A (UV $254 \mathrm{~nm}$ ) and of water volumes produced during a filter cycle were made. This way the average equivalent dose of PAC per filtrate volume was

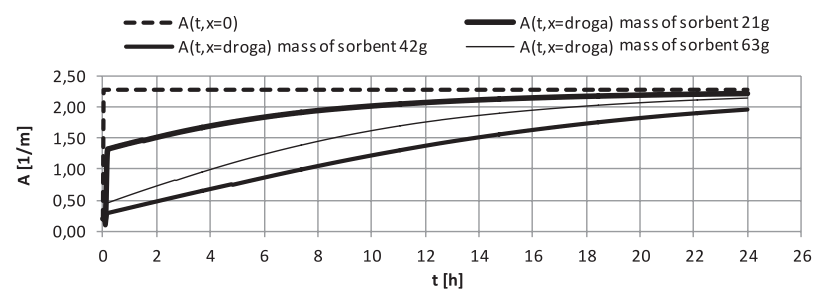

Fig. 7. Absorbance A versus time in the effluent from the PAC filter for different mass of sorbent (values $\mathrm{k}^{*} \mathrm{aM}, \Gamma$ for a given PAC mass; see "Effect filtration through the bed containing PAC" section in text). 
Table 2. Adsorption process in the filter with different masses of PAC.

\begin{tabular}{|c|c|c|c|c|}
\hline $\begin{array}{c}\text { PAC applied } \\
\text { to the filter } \\
\text { (g PAC) }\end{array}$ & $\begin{array}{c}\text { PAC applied to the } \\
\text { filter per unit volume } \\
(\text { empty bed) } \\
\left(\mathrm{kg} \mathrm{PAC} / \mathrm{m}^{3}\right)\end{array}$ & $\begin{array}{c}\text { Average absorbance } \\
\text { in the influent to the } \\
\text { PAC filter } \\
\mathrm{A}_{0}(1 / \mathrm{m})\end{array}$ & $\begin{array}{c}\text { Average absorbance } \\
\text { in the effluent from } \\
\text { the PAC filter } \\
\mathrm{A}(1 / \mathrm{m})\end{array}$ & $\begin{array}{c}\text { Avarage amount of organic pollutants } \\
\text { removed in the PAC filter } \\
\text { (absorbance units) } \\
\text { Simulation results } \\
\mathrm{a}_{1}\left(\mathrm{~m}^{3} /\left(\mathrm{m}^{*} \mathrm{~g}\right)\right)\end{array}$ \\
\hline 21 & 2.38 & 1.98 & 1.71 & 0.027 \\
\hline 42 & 4.75 & 2.05 & 1.15 & 0.045 \\
\hline 63 & 7.13 & 2.08 & 1.45 & 0.021 \\
\hline
\end{tabular}

determined $\left(\mathrm{D}_{1}\right)$ as well as the average amount of organic pollutants $\left(\mathrm{a}_{1}\right.$ in absorbance units) removed in the PAC filter (Table 1).

For the average Henry's constant $\Gamma\left(\Gamma=0.0128 \mathrm{~m}^{3} / \mathrm{g}\right.$ PAC) in the volume system, the authors calculated a presumed average amount of organic pollutants $\left(\mathrm{a}_{2}\right.$, in absorbance units) removed in a plug flow flocculator with PAC dosing. The value was calculated by multiplying $\Gamma$ and a difference between absorbance in the influent to the filter and absorbance [averaged over time] in the effluent from the filter without PAC; additionally, the effluent value was reduced by absorbance in the effluent from the PAC filter, averaged over filtration time, too. The PAC dose $\left(D_{2}\right)$ required for the flocculator was calculated on the basis of the ratio of the difference between absorbance in the effluent from the filter without PAC (averaged over time) and absorbance in the effluent from the PAC filter (averaged over time) and $\mathrm{a}_{2}$ (Table 1 ). The $\mathrm{D}_{2} / \mathrm{D}_{1}$ ratio indicates better utilization of PAC in the filter compared to the plug flow flocculator.

The $\mathrm{D}_{2} / \mathrm{D}_{1}$ ratio of required PAC doses can be used to compare applications of PAC in various systems in which the same average effluent concentrations of pollutants are expected. A characteristic feature of the $\mathrm{D}_{2} / \mathrm{D}_{1}$ ratios is their strong dependence on the mass of PAC applied to the filter bed. The maximum value were observed for $42 \mathrm{~g}$ PAC (equivalent PAC dose $22.7 \mathrm{~g} / \mathrm{m}^{3}$ ) and they ranged from 1.7 to 4.6 , with the average value of 3.3 (Table 1). In two other cases ( $21 \mathrm{~g}$ and $63 \mathrm{~g}$ of PAC) the ratios were several times smaller and their average values were 1.2 for the equivalent doses of 10.0 and $42.9 \mathrm{~g}$ of $\mathrm{PAC} / \mathrm{m}^{3}$ (Table 1). On the basis of pilot scale tests we can conclude that the efficiency of the PAC adsorption capacity in the filter can be few times higher than that observed during coagulation with simultaneous adsorption on PAC (the presently used method).

\section{Comparative Study on Removal of Organic Pollutants from Water with PAC (Process Modelling)}

Table 2 summarizes the results of adsorption simulation for different masses of PAC applied to the filter and the initial absorbance $\mathrm{A}_{0}=2.28 \mathrm{~m}^{-1}$. The simulation results

Table 3. The adsorption process in the filter with $42 \mathrm{~g}$ of PAC ( $4.75 \mathrm{~kg}$ PAC $/ \mathrm{m} 3$ of an empty bed) at different influent absorbances; the PAC layer $=0.50 \mathrm{~m}, \mathrm{k} *=3.52 \mathrm{E}-3(\mathrm{~m} / \mathrm{h}) *\left(\mathrm{~m}^{2} / \mathrm{g} \mathrm{PAC}\right), \Gamma=0.0181 \mathrm{~m}^{3} / \mathrm{g}$ PAC.

\begin{tabular}{|c|c|c|c|c|c|c|}
\hline $\begin{array}{l}\text { Filter } \\
\text { work } \\
\text { tme } \\
\text { (h) }\end{array}$ & $\begin{array}{c}\text { Absorbance in } \\
\text { the influent to } \\
\text { the PAC filter } \\
A_{0}(1 / \mathrm{m})\end{array}$ & $\begin{array}{l}\text { Average } \\
\text { absorbance } \\
\text { in the efflu- } \\
\text { ent from the } \\
\text { PAC filter } \\
\mathrm{A}^{\prime}{ }_{\mathrm{PWA}}(1 / \mathrm{m})\end{array}$ & $\begin{array}{l}\text { Removal of ora- } \\
\text { ganic pollutants } \\
\text { (as absorbance) } \\
(\%)\end{array}$ & $\begin{array}{l}\text { Average removal of } \\
\text { organic pollutants } \\
\text { in the PAC filter } \\
\text { (as absorbance) } \\
a_{1}\left(\mathrm{~m}^{3} /\left(\mathrm{m}^{*} \mathrm{~g}\right)\right)\end{array}$ & $\begin{array}{l}\text { Average removal of organic } \\
\text { substances } \\
\text { in the plug flow flocculator } \\
\text { with PAC } \\
\text { (as absorbance) } \\
\mathrm{a}_{2}\left(\mathrm{~m}^{3} /\left(\mathrm{m}^{*} \mathrm{~g}\right)\right) \\
\left(\Gamma=0.0128 \mathrm{~m}^{3} / \mathrm{g} \text { PAC }, \quad \mathrm{a}_{2}=\right. \\
\left.\Gamma^{*} \mathrm{~A}_{\mathrm{PWA}}^{\prime}\right) \\
\end{array}$ & $\begin{array}{l}\mathrm{D}_{2} / \mathrm{D}_{1} \\
\quad= \\
\mathrm{a}_{1} / \mathrm{a}_{2}\end{array}$ \\
\hline \multirow{3}{*}{18} & 2.28 & 1.09 & 52 & 0.044 & 0.014 & 3.1 \\
\hline & 3.00 & 1.44 & 52 & 0.058 & 0.018 & 3.2 \\
\hline & 4.00 & 1.91 & 52 & 0.078 & 0.024 & 3.3 \\
\hline \multirow{3}{*}{24} & 2.28 & 1.28 & 44 & 0.050 & 0.016 & 3.1 \\
\hline & 3.00 & 1.69 & 44 & 0.065 & 0.022 & 3.0 \\
\hline & 4.00 & 2.25 & 44 & 0.088 & 0.029 & 3.0 \\
\hline \multirow{3}{*}{48} & 2.28 & 1.72 & 25 & 0.056 & 0.022 & 2.5 \\
\hline & 3.00 & 2.26 & 25 & 0.074 & 0.029 & 2.6 \\
\hline & 4.00 & 3.01 & 25 & 0.099 & 0.039 & 2.5 \\
\hline
\end{tabular}




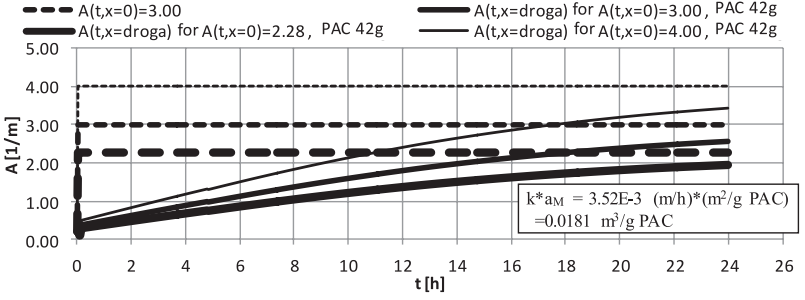

Fig. 8. Absorbance A in the effluent from the PAC filter vs. different influent absorbances.

are shown in Fig. 7. Absorbance $\mathrm{A}$ in the effluent from the PAC filter (42 g) increases very slowly over time. The highest applied dose of PAC (63 g) does not guarantee the best adsorption results (Fig. 7). The average amount of organic substances $\left(\mathrm{a}_{1}\right.$, in absorbance units) removed in the PAC filter was determined (Table 2) based on the simulations. This matches the average values $\mathrm{a}_{1}$ calculated from the experimental results (Tab. 1). This confirms a good fit of the adsorption model with the test results.

Table 3 shows the simulation results for the model with the PAC mass of $42 \mathrm{~g}$ for different operation times $(18,24$, and 48 hours) and different influent absorbance values $\left(2.28,3.00\right.$, and $\left.4.00 \mathrm{~m}^{-1}\right)$. The average amount of organic pollutants removed in the plug flow flocculator $\left(a_{2}\right)$ was calculated from the adsorption isotherm, since the adsorption process is very fast $\left(\mathrm{k}^{*} \mathrm{a}_{\mathrm{M}}=8.17916 \mathrm{E}-02(\mathrm{~m} / \mathrm{h}) *\left(\mathrm{~m}^{2} / \mathrm{g}\right.\right.$ PAC $)$ and runs virtually through the equilibrium states. Changes of the effluent absorbance in time as a function of influent absorbance are shown in Fig. 8. The curves show that at the lower influent absorbances and at the same time (e.g., $24 \mathrm{~h}$ ) the effluent absorbances are closer to the influent absorbances, while the ratios of effluent/influent absorbances remain the same. This means that the PAC exhaustion time does not depend on the influent absorbance (organic pollutants in the feed) at the absorbance range of 2.28 to $4.00 \mathrm{~m}^{-1}$.

Table 3 presents the average effluent absorbance for the PAC filter as well as other parameters: average amounts of substances removed per unit PAC mass applied to the filter $\left(a_{1}\right)$ and to the plug-flow flocculator $\left(a_{2}\right)$ and the ratio of the PAC doses $\left(D_{2} / D_{1}=a_{1} / a_{2}\right)$ required for PAC adsorption in the filter $\left(\mathrm{D}_{1}\right)$ and in coagulation with PAC adsorption $\left(D_{2}\right)$. The ratios $D_{2} / D_{1}$ changed from 2.5 to 3.3 and they decreased with higher PAC filter operation times. The ratios show a prevailing role of adsorption in the PAC filter if compared to PAC adsorption in the plug flow flocculator.

\section{Conclusions}

1. The PAC filter better utilizes adsorption capacity of the sorbent compared to the plug flow flocculator.

2. The experiments and simulation calculations have shown that when removing small amounts of organic pollutants the PAC filter showed about three times greater adsorption capacity than the volume system with PAC dosed.

3. There is an optimal range of the PAC mass applied per filter unit volume, at which maximum PAC adsorption efficiency is observed.

4. The mathematical models of adsorption developed for both volume system and PAC filter showed a very good fit to the measurements.

5. The equivalent doses of PAC applied to the filter could be even four times lower than the doses in the volume system required to achieve the same average effluent concentration of the adsorbate.

6. Overdosing of PAC does not increase the efficiency of PAC utilization in the filter.

7. Simulations have shown that the $\mathrm{D}_{2} / \mathrm{D}_{1}$ doses ratio increases with better efficiency of a pollutant removal from water.

8. Microscopic examination showed no presence of the PAC particles in the filtrate coming from this installation.

9. The advection and diffusion model of pollutant transport should be integrated using the decomposition method to reduce the distorting effects of numerical diffusion on the calculated concentrations and adsorption quantity.

10. It was established that the dimensionless concentration $\mathrm{C} / \mathrm{C}_{0}$ of certain substances, for absorbance $\mathrm{A}$ from 0 to about $4.0 \mathrm{~m}^{-1}$, varies approximately linearly.

\section{Acknowledgements}

This project was implemented in coordination with the Department of Kraków Waterworks.

The authors thank them for help implementing our research.

\section{References}

1. ADAMSKI W., SZLACHTA M., Water treatment technology - Principles and Modeling, Wroclaw University of Technology, 2011.

2. INA K., JOLL C., HEITZ A., Powdered activated carbon coupled with enhanced coagulation for natural organic matter removal and disinfection by-product control: Application in a Western Australian water treatment plant, Chemosphere 83, 661, 2011.

3. NAJM I.N., SNOEYINK V.L., LYKINS B.W., Adams J.Q., Using powdered activated carbon: A critical review, J. of theAm. Water Works Assoc., 83 (1), 65, 1991.

4. SANDRUCCI P., MERLO G., GENON G., MEUCCI L. PAC activity vs by-product precursors in water disinfection, Water Research, 29 (10), 2299, 1995.

5. NEWCOMBE G., MORRISON J., HEPPLEWHITE C. Simultaneous adsorption of MIB and NOM onto activated carbon. I. Characterization of the system end NOM adsorption, Carbon, 40 (12), 21352146, 2002.

6. NEWCOMBE G., MORRISON J., HEPPLEWHITE C., KNAPPE D.R.U. Simultaneous adsorption of MIB and NOM onto activated carbon. II. Competitive effects, Carbon, 40 (12), 2147, 2002. 
7. FABRIS R., CHOW C.W.K., DRIKAS M., Practical application of a combined treatment process for removal of recalcitrant NOM - alum and PAC, Water Science and Technology: Water Supply, 4 (4), 89, 2004.

8. UYAK V., YAVUZ S., TOROZ I., OZAYDIN S., GENCELI E.A., Disinfection by-products precursors removal by enhanced coagulation and PAC adsorption, Desalination, 216, 334, 2007.

9. CARRIERE A., VACHON M. , BELISLE J.-L., BARBEAU B., Supplementing coagulation with powdered activated carbon as a control strategy for trihalomethanes: application to an existing utility, Journal of Water Supply: Research and Technology, 58 (5), 363, 2009.

10. COULSON J.M., RICHARDSON J.F. Coulson and Richardson's Chemical Engineering Volume 1 - Fluid Flow, Heat Transfer and Mass Transfer, Elsevier, 1999.
11. BIELSKI A., Modelling of mass transport in watercourses considering mass transfer between phases in unsteady states. Part II. Mass transport during absorption and adsorption processes, Environment Protection Engineering, 37 (4), 2011.

12. BIELSKI A., Modelling of mass transport in watercourses at unsteady states, Environment Protection Engineering, $\mathbf{3 8}$ (3), 2012.

13. BIELSKI A., Modeling of pollutants transport in surface watercourses, Monograph 393, Kraków University of Technology, 2011.

14. BIELSKI A., ZYMON W., NOWAKOWSKI J., Raise efficiency of removing organic substances from treated waters in existing technological systems with powder activated carbon PAC, Department of Water Supply, Sewerage and Environmental Monitoring, Faculty of Environmental Engineering, Kraków University of Technology 2016. 
